\title{
Prevalence of Carbapenem Resistant Klebsiella and Proteus Clinical Isolates: A Real Threat to the Egyptian Health Care System
}

\author{
Nourhan H. Fanaki, Hoda M. Omar, Amal M. Khalil and Eva A. Edward* \\ Department of Microbiology and Immunology, Faculty of Pharmacy, Alexandria University, 1 \\ El Khartoum Sq., El Azareta, Alexandria, Egypt \\ *Corresponding author
}

\section{A B S T R A C T}

The worldwide spread of carbapenem-resistant Enterobacteriaceae (CRE) has become a major challenge in healthcare settings. This study aimed to screen the susceptibility to

\section{Keywords}

Klebsiella, Proteus vulgaris, Carbapenems,

Menthol, Polymerase

chain reaction,

Phenotypic methods

Article Info

Accepted:

16 March 2018

Available Online:

10 April 2018 imipenem and meropenem, among 49 Klebsiella and 7 Proteus vulgaris clinical isolates from Egypt. The combinations of carbapenems with ciprofloxacin, rifampicin, amikacin and colistin were tested against CRE. Attempts to cure plasmids mediating carbapenem resistance using menthol, as a natural curing agent, as well as to test its efficacy when combined with other antibiotics against CRE, were done. A comparison was done between phenotypic methods and polymerase chain reaction for the differentiation of carbapenemases. Among our isolates, 80.36 and $843.93 \%$ were resistant to imipenem and meropenem, respectively. The tested carabpenem/antibiotic combinations proved their efficacy against CRE. Menthol showed good curing rates (up to 100\%) for carbapenem resistance plasmids. Also, in $71.43 \%$ of the studied cases, it improved the efficacy of the tested combinations. Polymerase chain reaction was more precise for the detection of carbapenemases. Among the tested isolates, bla $a_{N D M}$ and bla $a_{O X A-48-l i k e}$ were the most prevalent carbapenemases. Our results demonstrated that carbapenem resistant Klebsiella and Proteus vulgaris clinical isolates have become a serious threat in Egypt. Combination therapy including menthol was the most appropriate for combating CRE.

\section{Introduction}

The war against multidrug-resistant bacteria is very challenging and of a great concern worldwide. Media attention on antibiotic resistance has focused in the recent years on the Gram-positive cocci. However, the Gramnegative bacilli, especially Enterobacteriaceae, have begun to take the center stage clinically (Logan, 2012). Among the pathogens that are considered to be of particular concern are the carbapenem-resistant

Enterobacteriaceae (CRE) (Kanj and Kanafani, 2011).

Carbapenems act as mechanism-based inhibitors of the peptidase domain of PBPs. They possess a broad spectrum of activity against both Gram-positive and Gramnegative bacteria. Consequently, they are often used as "last-line agents" when infected patients are gravely ill (Papp-Wallace et al., 2011). In Enterobacteriaceae, resistance to 
carbapenems arises from two main mechanisms: (i) non- carbapenemasemediated carbapenem resistance and, (ii) carbapenemase-mediated carbapenem resistance (Nordmann et al., 2012). The worldwide spread of CRE has become a major challenge (Yamamoto and Pop-Vicas, 2014). Unfortunately, the antibiotics available for clinicians for treating CRE infections are really very few. Among the "drugs of last resort", for treating CRE infections, there are polymyxins, aminoglycosides, tigecycline and fosfomycin. Carbapenem therapy, mostly in combination regimens, might play a significant role, but, still, this role remains to be determined (Perez and Van Duin, 2013).

Among the most important members of the Enterobacteriaceae family are the Klebsiella spp. and the Proteus spp. Klebsiella is well known as a common cause of pneumonia (Podschun and Ullmann, 1998), bacteremia, septicemia and urinary tract infections (Jamil et al., 2014). Also, Proteus bacilli can result in various types of infections, including infections of the urinary tract and the respiratory tract (Rozalski et al., 1997).

The objectives of our study were: (i) the detection of the resistance to both carbapenems: imipenem (IPM) and meropenem (MEM) among different Klebsiella and Proteus vulgaris clinical isolates, in Egypt, (ii) studying the efficacy of different carbapenem/antibiotic combinations for the eradication of CRE, (iii) curing the plasmids mediating carbapenem resistance, from selected CRE isolates, using menthol as a natural curing agent, as well as testing its efficacy when used in combination with other antibiotics against CRE, (iv) differentiation of carbapenemases among selected isolates using three different phenotypic methods and (v) screening for genes encoding for carbapenemases among selected CRE isolates using the polymerase chain reaction (PCR).

\section{Materials and Methods}

\section{Bacterial strains}

Forty-nine Klebsiella and $7 \quad P$. vulgaris clinical isolates were collected from different specimens of Egyptian patients, from three different governorates in Egypt: Alexandria, Cairo and Al Beheira. They were identified by classical microscopical and biochemical methods (Bailey et al., 1986). Commonly used Klebsiella clinical isolates, in this study, were selected to be further identified to the species level by the Matrix-Assisted Laser Desorption/Ionization - Time of Flight (MALDI-TOF) mass spectrometry (De Carolis et al., 2014) using the MALDI Biotyper (Bruker Daltonik, USA).

\section{Determination of the minimum inhibitory concentration (MIC) of the tested antibiotics among different clinical isolates}

The MICs of both IPM and MEM were determined against all the isolates using the agar dilution technique (Barry, 1986). As a prerequisite for the checkerboard test and the time-kill assay, the MICs of IPM, MEM, ciprofloxacin (CIP), rifampicin (RA), colistin (COL), amikacin (AK) were determined against selected isolates using the broth dilution technique (Andrews, 2001).

The antimicrobial agents used in this study were purchased from community pharmacies in Alexandria: amikacin (as amikacin sulphate), Amikin ${ }^{\circledR} 500 \mathrm{mg}$ (Smithkline Beecham, Egypt), ciprofloxacin (as lactate), Ciprofloxacin® $200 \mathrm{mg} / 100 \mathrm{~mL}$ (AMRIYA PHARM. IND.), colistin (as colistimethate sodium), Colomycin ${ }^{\circledR} 1$ million IU (Forest Laboratories, UK), imipenem, Tienem ${ }^{\circledR} 500$ mg (Merch Sharp and dohme B/V), meropenem, Meronem ${ }^{\circledR}$ 1g (Astrazenca, UK) and rifampicin, Rimactane ® $300 \mathrm{mg}$ (SANDOZ). 
Studying the efficacy of different carbapenem/antibiotic combinations for the eradication of CRE using the checkerboard technique (Krogstad and Moellering, 1986)

The tested antibiotic combinations were: IPM/RA, IPM/AK, IPM/CIP, IPM/COL, MEM/RA, MEM/AK, MEM/CIP and MEM/COL. The antibacterial activity of each combination was determined by calculating the Fractional Inhibitory Concentration (FIC) index, as described by Fernandez-Cuenca et $a l$., (2003). FIC index value of $<0.5$ indicated synergism, while an index value of $>0.5-0.75$ indicated moderate synergism. Additivity was indicated by FIC index value of $>0.75-<2$ and antagonism by an index value of $>2$.

Curing of plasmids mediating carbapenem resistance, from selected CRE isolates, using menthol as a natural curing agent

At first, the MIC of menthol (BORG Pharmaceutical Ind., Egypt) was determined using the broth dilution method (Andrews, 2001). Then, the curing experiment was done using different concentrations of menthol (Kon and Rai, 2012; Sachan et al., 2013), as a natural curing agent. The tested menthol concentrations were: the concentration reported in the literature (Kon and Rai, 2012): $0.325 \mathrm{mg} . \mathrm{ml}, 2 \mathrm{X}$ this concentration $(0.65$ $\mathrm{mg} / \mathrm{ml})$ and $3 X$ the same concentration $(0.975$ $\mathrm{mg} / \mathrm{ml})$. At each time ten $\mathrm{mL}$ aliquots of sterile Müller-Hinton broth containing the specified menthol concentration were aseptically distributed in sterile flasks and inoculated with $0.2 \mathrm{~mL}$ of overnight broth culture of the tested organism. The mixtures were shaken gently at $37^{\circ} \mathrm{C}$ for 24 hours at $250 \mathrm{rpm}$, then, diluted and spread over the surface of sterile nutrient agar plates. After overnight incubation at $37{ }^{\circ} \mathrm{C}, \quad 200$ representative colonies were aseptically picked up onto sterile nutrient agar plates as master plates, as well as two antibiotic plates (one containing $1 / 2 \mathrm{MIC}$ of IPM and the other containing $1 / 2$ MIC of MEM). The plates were incubated at $37^{\circ} \mathrm{C}$ for 24 hours, then, examined for the presence of the cured colonies. The curing rate $(\%)$ was calculated as follows:

No. of cured colonies

Curing rate $(\%)=$---------------------- X 100

Total no. of tested colonies

The time-kill assay for the triple combinations of menthol, a carbapenem (IPM or MEM) and a third antibiotic against representative carbapenem resistant isolates (Krogstad and Moellering, 1986)

The antibiotic combinations tested were the same as those tested by the checkerboard technique, but after the addition of menthol. The antibiotic solutions were prepared to reach final concentrations equivalent to those which yielded the lowest FIC indices in the checkerboard experiment. A concentration of menthol equivalent to $0.975 \mathrm{mg} / \mathrm{ml}$ was tested (the concentration which achieved the best curing rates of carbapenem resistance plasmids). For each tested isolate, six test tubes were prepared. The first test tube received a single carbapanem (IPM or MEM), the second received the other antibiotic (RA, AK, CIP or COL). The third received menthol and the fourth received both the carbapenem (IPM or MEM) and one of the other tested antibiotics (RA, AK, CIP or COL).

The fifth test tube received the triple combination of one of the carbapenems (IPM or MEM) plus one of the other antibiotics (RA, AK, CIP or COL) plus menthol, while the sixth test tube received only sterile distilled water as a control. The final volume in all test tubes was $10 \mathrm{ml}$. The organism was diluted and added to each test tube to reach a 
final count of approximately $10^{6} \mathrm{CFU} / \mathrm{ml}$. The results were presented as curves relating log number of survivors per $\mathrm{mL}$ against the killing time (at 3, 6 and 24 hours). The results were interpreted as described by Chambers and Sande (1996). Synergistic interaction was defined as $\geq 2 \log _{10}$ decrease in survivors between the combination and the most active constituent. Additive effect was defined as < $1 \log _{10}$ change (increase or decrease) in killing when comparing the combination with the most active single drug alone. Antagonism was described as $>2 \log _{10}$ decrease in killing for the combination in comparison to the most active single drug alone. The combination was compared to the most active single drug alone at any point along the time-kill curve $(3,6$, or 24 hours) (all time periods were evaluated).

Determination of the effect of menthol on the ultrastructure of a selected Klebsiella isolate by examination using transmission electron microscopy (TEM)

TEM was used to examine the effect of menthol on the ultrastructure of the cells of the $K$. pneumoniae isolate (K89), according to Kim et al., (2007), using the transmission electron microscope (JEOL, CX 100, Japan).The effect of menthol (in a concentration equivalent to $1 / 16$ MIC) on the treated bacterial cells was compared with a control sample of untreated K89. The sample preparation and examination were carried out at the Electron Microscopy Unit, Faculty of Science, Alexandria University.

Phenotypic methods for the differentiation of carbapenemases in carbapenem-resistant clinical isolates

Three different phenotypic methods were carried out for the differentiation of carbapenemases among 37 selected CRE isolates, classified as follows: 35 Klebsiellaand 2 P. vulgaris isolates. These three methods were:
The inhibitor based method (Datta et al., 2012)

Phenyl boronic acid (PBA), or ethylenediaminetetra acetic acid (EDTA) or both together with meropenem disc were used for the detection of KPC and MBL enzymes, respectively. The stock solution of PBA, in the concentration of $20 \mathrm{mg} / \mathrm{mL}$, was prepared by dissolving PBA in dimethyl sulfoxide (DMSO). Twenty microliters (400 $\mu \mathrm{g}$ of PBA) from this solution were aseptically dispensed onto meropenem discs. The stock solution of EDTA was prepared by dissolving anhydrous disodium EDTA in distilled water at a concentration of $0.1 \mathrm{M}$. Ten microliters (292 $\mu \mathrm{g}$ of EDTA) from this solution were aseptically dispensed onto meropenem discs. The meropenem discs, with the added inhibitor (s), were dried and used within 60 min. On a Müller-Hinton agar plate inoculated with the test strain, four discs of meropenem were used. One disc of meropenem was without any inhibitor, one disc had PBA (400 $\mu \mathrm{g})$ only, one disc had EDTA (292 $\mu \mathrm{g})$ only and the fourth meropenem disc had both PBA plus EDTA (in the same previously mentioned concentrations). In addition, two other discs with the concentrations of PBA and EDTA employed in this experiment were also included on the same plate, as controls, so as to make sure that such concentrations of PBA and EDTA did not show any detectable effect on the bacterial growth. The agar plates were then incubated at $37{ }^{\circ} \mathrm{C}$ overnight and the diameters of the inhibition zones around these meropenem discs with the added inhibitor (s) were compared with the diameter around the plain meropenem disc. The results were interpreted according to Datta et al., (2012).

The imipenem-EDTA double disc synergy test (Lee et al., 2003)

The detection of metallo- $\beta$-lactamases was performed by the double disc synergy method. A $10 \mu$ gimipenem disc was aseptically placed 
in the center of a Müller-Hinton agar plate inoculated with the test strain. An EDTA disc $(1900 \mu \mathrm{g})$ was aseptically placed at a distance of $15 \mathrm{~mm}$ center to center from the imipenem disc. The plate was incubated at $37{ }^{\circ} \mathrm{C}$ overnight. The zone around the imipenem disc would be extended on the side nearest the EDTA disc for a metallo- $\beta$-lactamase producer.

The modified Hodge test (MHT) (Parveen et al., 2010)

MHT was carried out to, according to Parveen et al., (2010), to detect the production of carbapenemases among the tested isolates.

Detection of resistance genes to carbapenems among selected carbapenemresistant isolates using PCR (Aubron et al., 2005; Navon-Venez et al., 2006; Cabral et al., 2012; Doyle et al., 2012; Hong et al., 2012; Kaase et al., 2012; Shahid et al., 2012; Wendel et al., 2013; Zeitoun et al., 2015):

The distribution of genes responsible for resistance to IPM and MEM was screened among 13 selected carbapenem resistant isolates, classified as: 11 Klebsiella isolates and $2 P$. vulgaris isolates. The used primers are listed in Table 1. In addition, the gene for $16 S$ r RNA (Zeitoun et al., 2015) was included in the test, as a positive control.

All primers used in this study were purchased from Macrogencompany (Seoul, Republic of South Korea). PCR reactions were conducted in the thermocycler apparatus (Perkin Elmer, Gene Amp PCR system). The amplified samples were then analyzed by agarose gel electrophoresis using $1.7 \%$ agarose gels that had been prestained with ethidium bromide. The bands of the amplified products were visualized on a $254 \mathrm{~nm}$ UV transilluminator (Entela UVP Upland CA 91786, USA).

\section{Results and Discussion}

\section{Bacterial strains}

The collected isolates were identified as follows: forty-nine (87.5\%) Klebsiella spp. and seven $(12.5 \%)$ P. vulgaris. Concerning the results of the MALDI-TOF mass spectrometry, 12 (out of 18 selected) Klebsiella isolates were identified as $K$. pneumoniae. On the other hand, 6 isolates were identified as $K$. variicola.

Determination of the minimum inhibitory concentration (MIC) of the tested carbapenems: IPM and MEM among different clinical isolates

Out of the fifty-six tested isolates, 45 isolates were resistant to IPM, while 47 isolates were resistant to MEM.

In case of the tested Klebsiella isolates, 39 isolates were found to be resistant to both IPM and MEM, while in case of the $P$. vulgaris isolates, 2 isolates (P4 and P10) were resistant to both carbapenems.

Studying the efficacy of different carbapenem/antibiotic combinations for the eradication of CRE using the checkerboard technique

The chosen combinations were tested against 9 selected CRE isolates: 7 Klebsiella isolates (K. pneumoniae K44, K76, K81, K85, K89 and $K$. variicola $\mathrm{K} 37, \mathrm{~K} 56)$ and $2 P$. vulgaris isolates (P4 and P10). However, the combinations of carbapenems (IPM and MEM) with colistin (COL) were not tested against the $P$. vulgaris clinical isolates, as colistin has no activity against Proteus spp. (Conly and Johnston, 2006). The efficacy of all tested combinations varied between synergism, moderate synergism and additivity. No antagonism was detected at all. 
Regarding IPM/CIP combinations, a synergistic effect was detected in case of K37, K76 and P4 (FIC indices $=0.5,0.375$ and 0.5, respectively). For IPM/RA combinations, synergism was observed in case of K37, K56, $\mathrm{K} 44$ and P10 (FIC indices $=0.313,0.5,0.25$ and 0.375 , respectively). In case of IPM/AK combinations, synergism was obtained in case of $\mathrm{K} 37, \mathrm{~K} 56, \mathrm{~K} 81, \mathrm{~K} 85$ and $\mathrm{P} 4$ (FIC indices= $0.25,0.5,0.5,0.375$ and 0.313 , respectively). For IPM/COL combinations, a synergistic effect was noticed in case of K37, K44 and K76 (FIC indices $=0.5,0.375$ and 0.5 , respectively).

Concerning MEM/CIP combinations, a synergistic effect was only detected in case of K44, K76 and K81 (FIC indices $=0.375,0.375$ and 0.313 , respectively). For MEM/RA combinations, synergism was observed in case of K44, K81 and P10 (FIC indices $=0.5,0.188$ and 0.25 , respectively). Regarding MEM/AK combinations, a synergistic effect was obtained in case of K37, K44, K81 and P4 $(\mathrm{FIC}$ indices $=0.188,0.313,0.375$ and 0.375 , respectively). In case of $\mathrm{MEM} / \mathrm{COL}$ combinations, synergism was noticed in case of K37, K56, K44, K76, K81 and K85 (FIC indices $=0.188,0.375,0.313,0.375,0.375$ and 0.375 , respectively).

Curing of plasmids responsible for carbapenem resistance using different concentrations of menthol as a natural curing agent

Four CRE isolates were selected for the curing experiment: $3 \mathrm{~K}$. pneumoniae isolates (K48, $\mathrm{K} 58$ and $\mathrm{K} 89$ ) and $1 P$. vulgaris isolate (P10). The MIC of menthol was $8192 \mu \mathrm{g} / \mathrm{mL}$ against K48, K58 and K89. However, for P10, it was $4096 \mu \mathrm{g} / \mathrm{mL}$.

Concerning the results of the curing experiment, and in case of K48, upon using menthol concentrations equivalent to $1 \mathrm{X}, 2 \mathrm{X}$ and $3 \mathrm{X}$ the published concentration, curing rates of $0.5,1.5$ and $5.5 \%$, respectively, were obtained. For K58, and when using $1 \mathrm{X}$ and $2 \mathrm{X}$ the reported concentration of menthol, curing rates of 0.5 and $2 \%$ were obtained, respectively. The most promising effect was observed upon applying a menthol concentration equivalent to $3 \mathrm{X}$ the reported concentration where a curing rate of $100 \%$ was obtained. For both isolates K89 and P10, both concentrations of menthol equivalent to $1 \mathrm{X}$ and $2 \mathrm{X}$ the reported concentration failed to cure carbapenem resistance plasmids. However, upon applying menthol in a concentration equal to $3 \mathrm{X}$ the published concentration, a curing rate of $1.5 \%$ was detected.

The time-kill assay for the triple combinations of menthol, a carbapenem (IPM or MEM) and a third antibiotic against representative carbapenem resistant isolates

The studied combinations were tested against 2 representative CRE isolates: $K$. pneumoniae K89 and P. vulgaris P10. However, in case of carbapenem/colistin combination, P10 was not included. We compared the efficacy of each of the eight tested triple combinations with that of the combinations of the two antibiotics alone (without menthol) in order to investigate the effect of menthol when added to carbapenem/antibiotic combinations for the eradication of CRE. In 4 (out of 14 tested) combinations, a synergistic effect was observed when menthol was added to the antibiotic combinations, while only an additive effect was noticed when the combinations were tested without menthol. These combinations were: IPM/CIP/Menthol combination against P10, IPM/RA/Menthol combination against K89, IPM/RA/Menthol combination against P10 and MEM/RA/Menthol combination against P10 
(Fig. 1). In other 6 (out of 14 tested) combinations, the addition of menthol to the tested combinations enhanced the synergistic effect that was obtained upon trying such combinations without menthol. These combinations were: IPM/CIP/Menthol combination against K89, MEM/CIP/Menthol combination against K89, MEM/RA/Menthol combination against K89, IPM/AK/Menthol combination against K89, IPM/COL/Menthol combination against K89 (Fig. 2) and MEM/COL/Menthol combination against K89. Concerning the four remaining combinations, the addition of menthol showed either no considerable difference compared to the combinations of two antibiotics (without menthol), or just resulted in an additive effect. However, no antagonism was detected in any of the tested combinations.

Determination of the effect of menthol on the ultrastructure of a selected Klebsiella isolate by examination using TEM

Control cells of $K$. pneumoniae (K89) isolate appeared under TEM as normal rod-shaped cells with an intact outer membrane (Fig. 3). In contrast, menthol-treated cells of K89 showed rupture of the outer membrane and presence of numerous pores in the membrane. This led to the leakage of the intracellular components of such treated cells (Fig. 4).

Phenotypic methods for the differentiation of carbapenemases in carbapenem-resistant clinical isolates

The obtained results showed that 29 (out of the thirty-seven tested) isolates were considered to be MBL producers according to both the inhibitor based method and the imipenem-EDTA double disc synergy test. Concerning the remaining 8 isolates, they were considered to be negative for both KPC and MBL, by the inhibitor based method, as well as non-MBL producers, according to the
imipenem-EDTA double disc synergy test. These eight isolates were: 7 Klebsiella isolates (K40, K53, K64, K67, K77, K86 and K92) and $1 P$. vulgaris isolate $(\mathrm{P} 4)$. On the other hand, according to the results of the MHT, all the thirty-seven tested isolates were found to be carbapenemase producers.

Detection of genes encoding for carbapenemases among selected carbapenem-resistant isolates using PCR

The distribution of genes encoding for carbapenemases was screened among $13 \mathrm{CRE}$ clinical isolates, classified as follows: $2 P$. vulgaris isolates (P4 and $\mathrm{P} 10), 8 K$. pneumoniae isolates (K44, K45, K48, K58, $\mathrm{K} 62, \mathrm{~K} 73, \mathrm{~K} 81$ and $\mathrm{K} 89$ ) and $3 \mathrm{~K}$. variicola isolates (K40, K77 and K92). Concerning the genes encoding for class A carbapenemases, bla $_{I M I}$ was detected in K44, K45 and K48. On the other hand, $b l a_{N M C}$ was only detected in K58.

Among the six tested genes encoding for class B carbapenemases, $b l a_{S P M}$, it was detected in K81, while bla $a_{N D M}$, being the most predominant gene, was detected in 10 isolates: P10, K40, K44, K45, K48, K58, K73, K77, K89 and K92 (Fig. 5). Regarding the genes encoding for class D carbapenemases, bla OXA- $_{\text {- }}$ 48-like was detected in 5 isolates: K40, K73, K77, K89 and K92 (Fig. 6).

Comparison between different phenotypic methods and the genotypic method (PCR) for the differentiation of carbapenemases among selected CRE clinical isolates

A comparison was done between the results obtained from the tested phenotypic methods and those of PCR among the thirteen isolates for which screening for the carbapenemases was done both phenotypically and genotypically. This comparison could be summarized in Table 2. 
Table.1 Primers of the carbapenemase genes
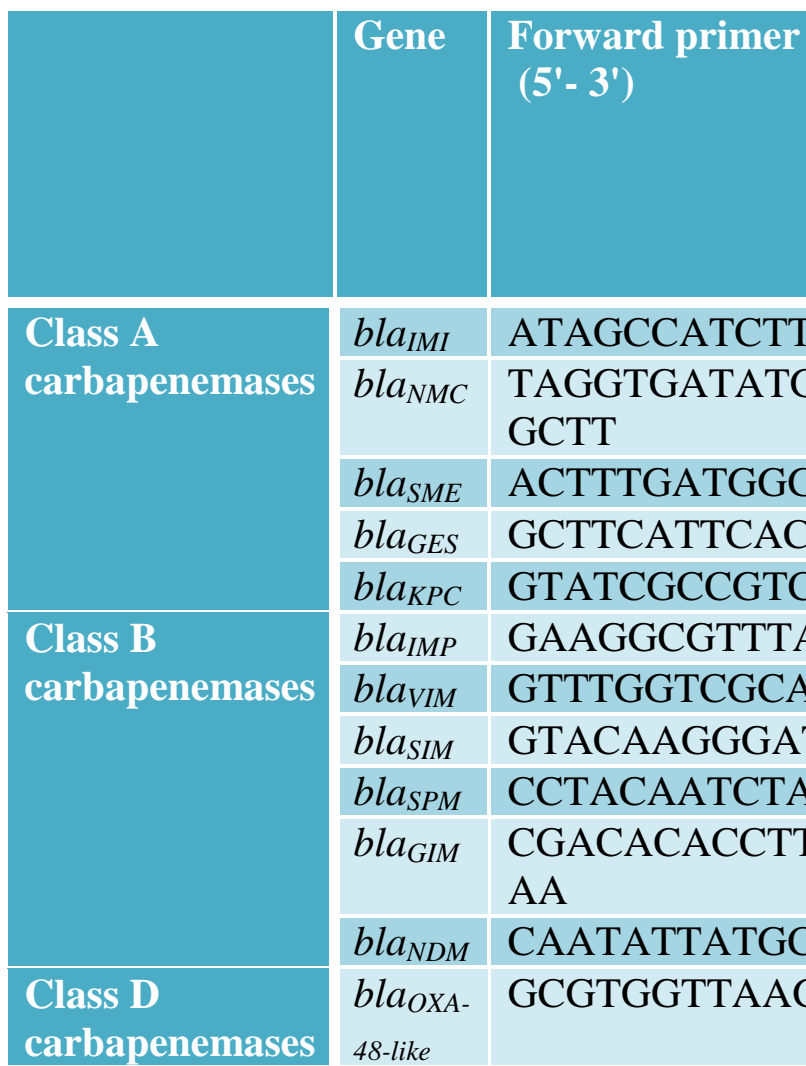

Size of

the

amplified

product in

base pairs

(bp)

TCTGCGATTACTTTATCCTC 818

ACTGCTGCAGGTGTAGATGTGT 205

CA

ACGAATTCGAGCATCACCAG 551

CGATGCTAGAAACCGCTC 323

\begin{tabular}{|l|l|}
\hline GGTCGTGTTTCCCTTTAGCC & 637 \\
\hline
\end{tabular}

GTAAGTTTCAAGAGTGATGC 587

AATGCGCAGCACCAGGATAG 382

TGGCCTGTTCCCATGTGAG 569

TCGCCGTGTCCAGGTATAAC 649

GATGCTAGCCATAACCTGGTAT 82

$\mathrm{CC}$

CCTTGCTGTCCTTGATCAGG 632

CATCAAGTTCAACCCAACCG 438

Table. 2 Comparison between different phenotypic methods and PCR for the differentiation of carbapenemases among selected CRE clinical isolates

\begin{tabular}{|c|c|c|c|c|}
\hline \multirow{2}{*}{$\begin{array}{l}\text { Isolate } \\
\text { code }\end{array}$} & \multicolumn{3}{|c|}{ Phenotypic methods } & \multirow[t]{2}{*}{ PCR } \\
\hline & MHT & $\begin{array}{c}\text { Inhibitor based } \\
\text { method }\end{array}$ & $\begin{array}{l}\text { Double disc } \\
\text { synergy test }\end{array}$ & \\
\hline $\begin{array}{l}\text { P10, K44, } \\
\text { K45, } \\
\text { K48, K58, } \\
\text { K73, } \\
\text { K81, K89 } \\
\end{array}$ & $\begin{array}{l}\text { Carbapenemase } \\
\text { producers }\end{array}$ & $\mathrm{MBL}^{\mathrm{a}}$ producers & MBL producers & MBLs were detected \\
\hline K62 & $\begin{array}{l}\text { Carbapenemase } \\
\text { producer }\end{array}$ & MBL producer & MBL producer & $\begin{array}{l}\text { No carbapenemase genes } \\
\text { were detected }\end{array}$ \\
\hline $\begin{array}{l}\text { K40, K77, } \\
\text { K92 }\end{array}$ & $\begin{array}{l}\text { Carbapenemase } \\
\text { producers }\end{array}$ & $\begin{array}{l}\text { Negative for both } \\
\text { MBL } \\
\text { and } \mathrm{KPC}^{\mathrm{b}}\end{array}$ & $\begin{array}{l}\text { Non-MBL } \\
\text { producers }\end{array}$ & MBLs were detected \\
\hline P4 & $\begin{array}{l}\text { Carbapenemase } \\
\text { producer }\end{array}$ & $\begin{array}{l}\text { Negative for both } \\
\text { MBL } \\
\text { and KPC }\end{array}$ & $\begin{array}{l}\text { Non-MBL } \\
\text { producer }\end{array}$ & $\begin{array}{l}\text { No carbapenemase genes } \\
\text { were detected }\end{array}$ \\
\hline
\end{tabular}

${ }^{\mathrm{a}}$ : MBL: metallo- $\beta$ - lactamase.

${ }^{\mathrm{b}}$ : KPC: Klebsiella pneumoniae carbapenemase. 
Fig.1 Comparative bactericidal activity of MEM $(1 \mu \mathrm{g} / \mathrm{mL}), \mathrm{RA}(256 \mu \mathrm{g} / \mathrm{mL})$ and menthol $(0.975 \mathrm{mg} / \mathrm{mL})$ each alone and in combination against the $P$. vulgaris clinical isolate $(\mathrm{P} 10)$

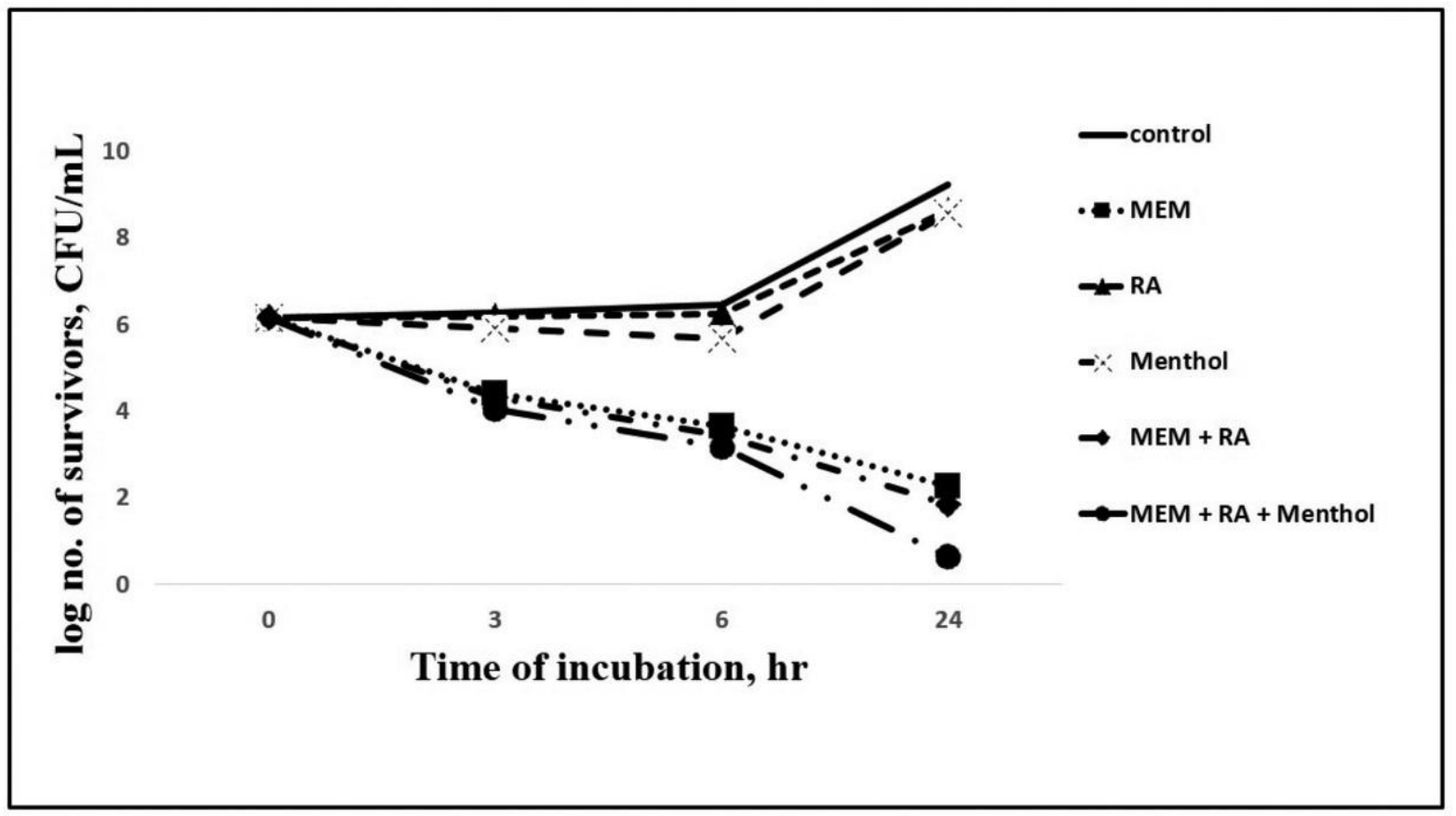

Fig.2 Comparative bactericidal activity of IPM $(16 \mu \mathrm{g} / \mathrm{mL})$, COL $(0.25 \mu \mathrm{g} / \mathrm{mL})$ and menthol $(0.975 \mathrm{mg} / \mathrm{mL})$ each alone and in combination against the $K$. pneumoniae clinical isolate (K89)

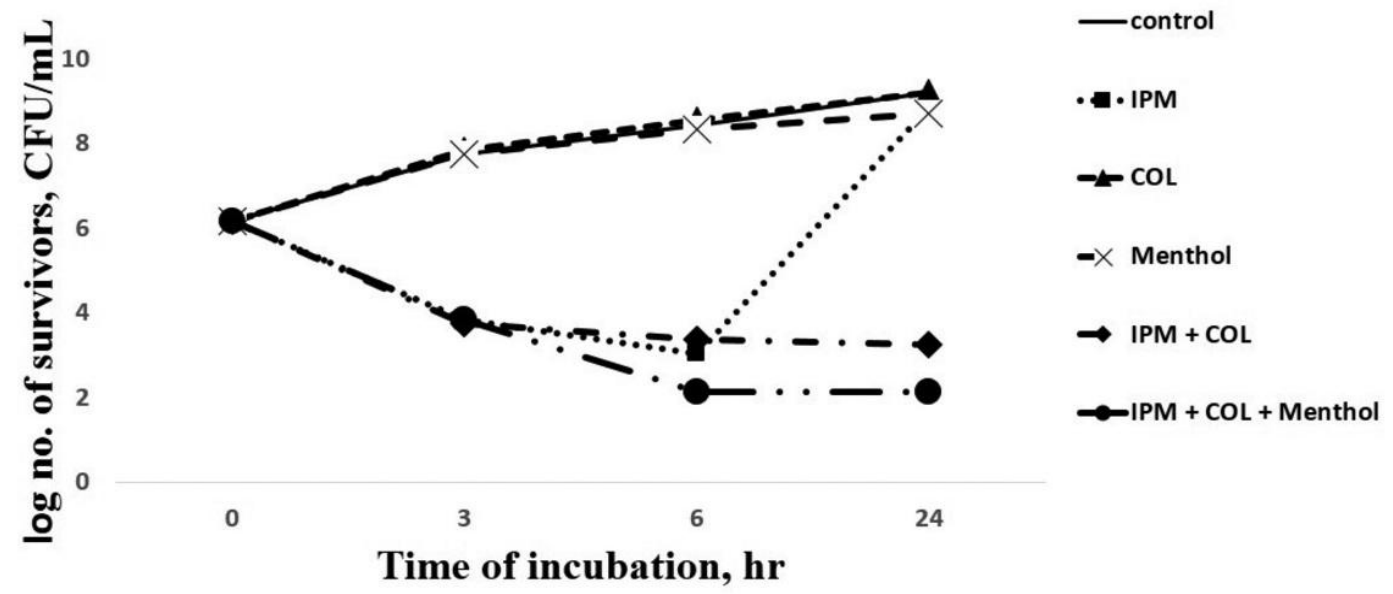


Fig.3 TEM demonstrating cells of the control (untreated) K. pneumoniae clinical isolate (K89) appearing as normal rod-shaped bacterial cells with intact outer membrane

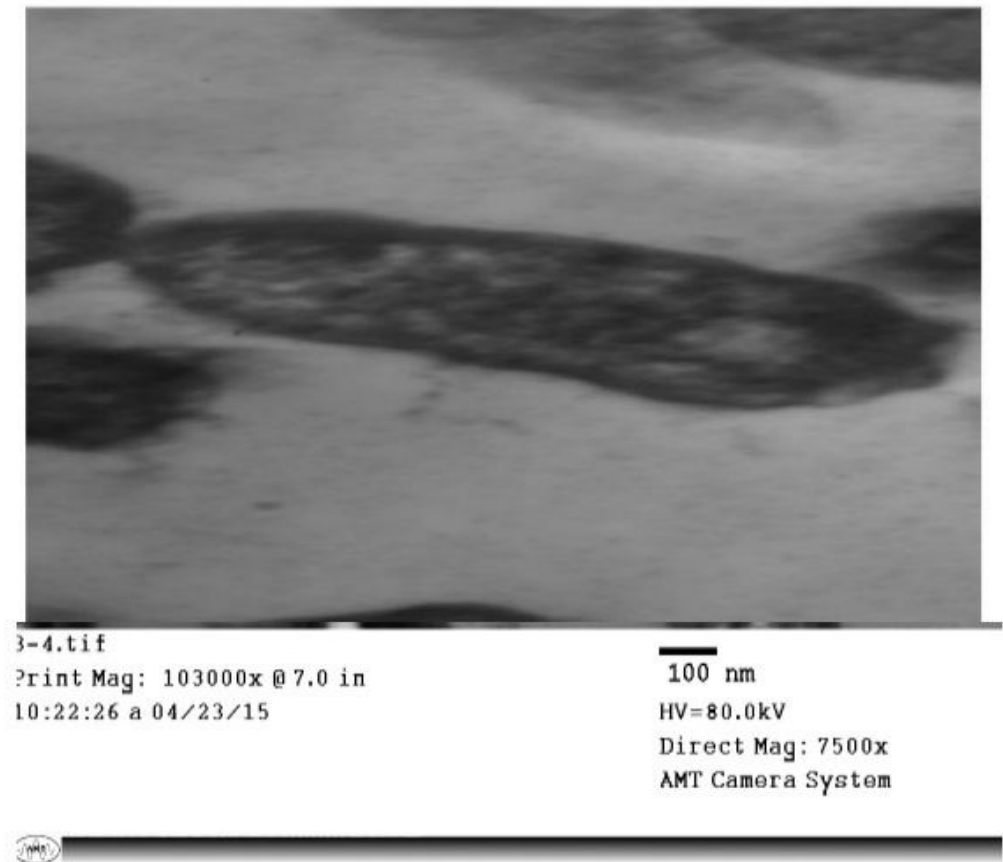

Fig.4 TEM demonstrating cells of the menthol-treated $K$. pneumoniae clinical isolate (K89) showing rupture and pores in the outer membrane (indicated by arrows) and leakage of the intracellular components

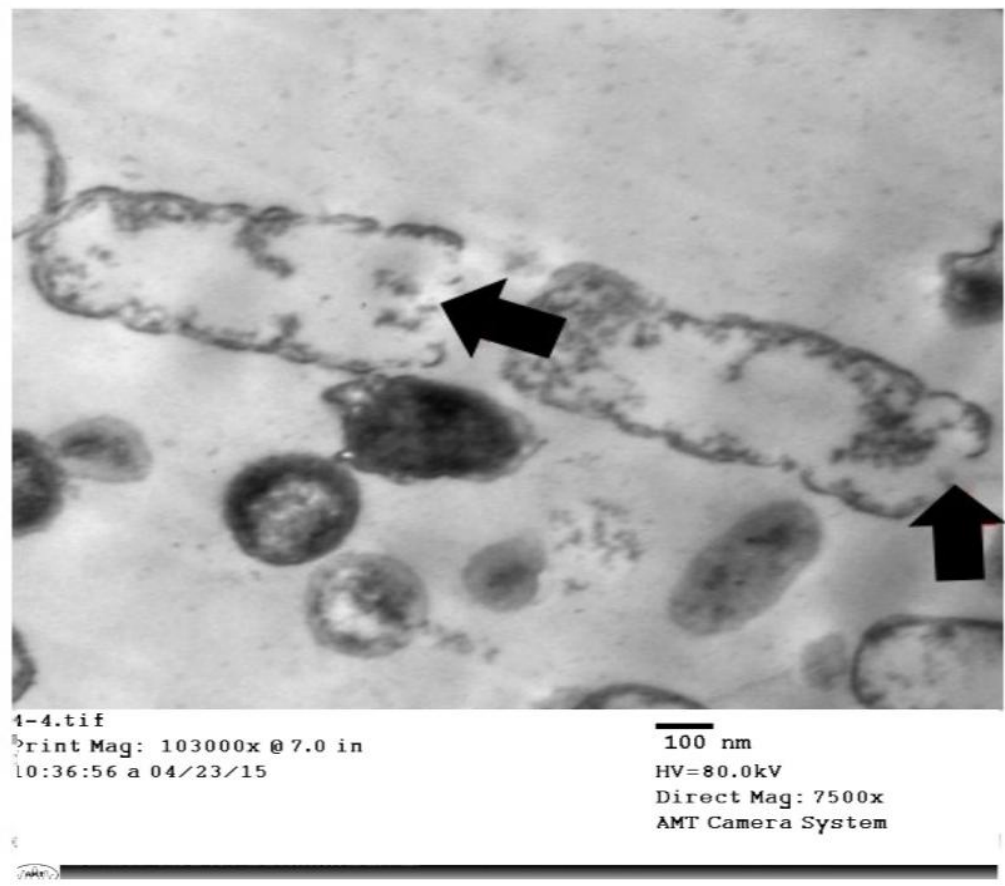


Fig.5 PCR amplification of the constitutive genes encoding for class B carbapenemases $\left(b l a_{N D M}\right)$ (632 bp) in selected CRE clinical isolates. Lanes: 1: P10; 2: K48; 3: 100 bp DNA ladder; 4: K89;

5: K58; 6: K44; 7: K73; 8: K45; 9: K40; 10: K92; 11: K77; and 12: 100 bp DNA ladder

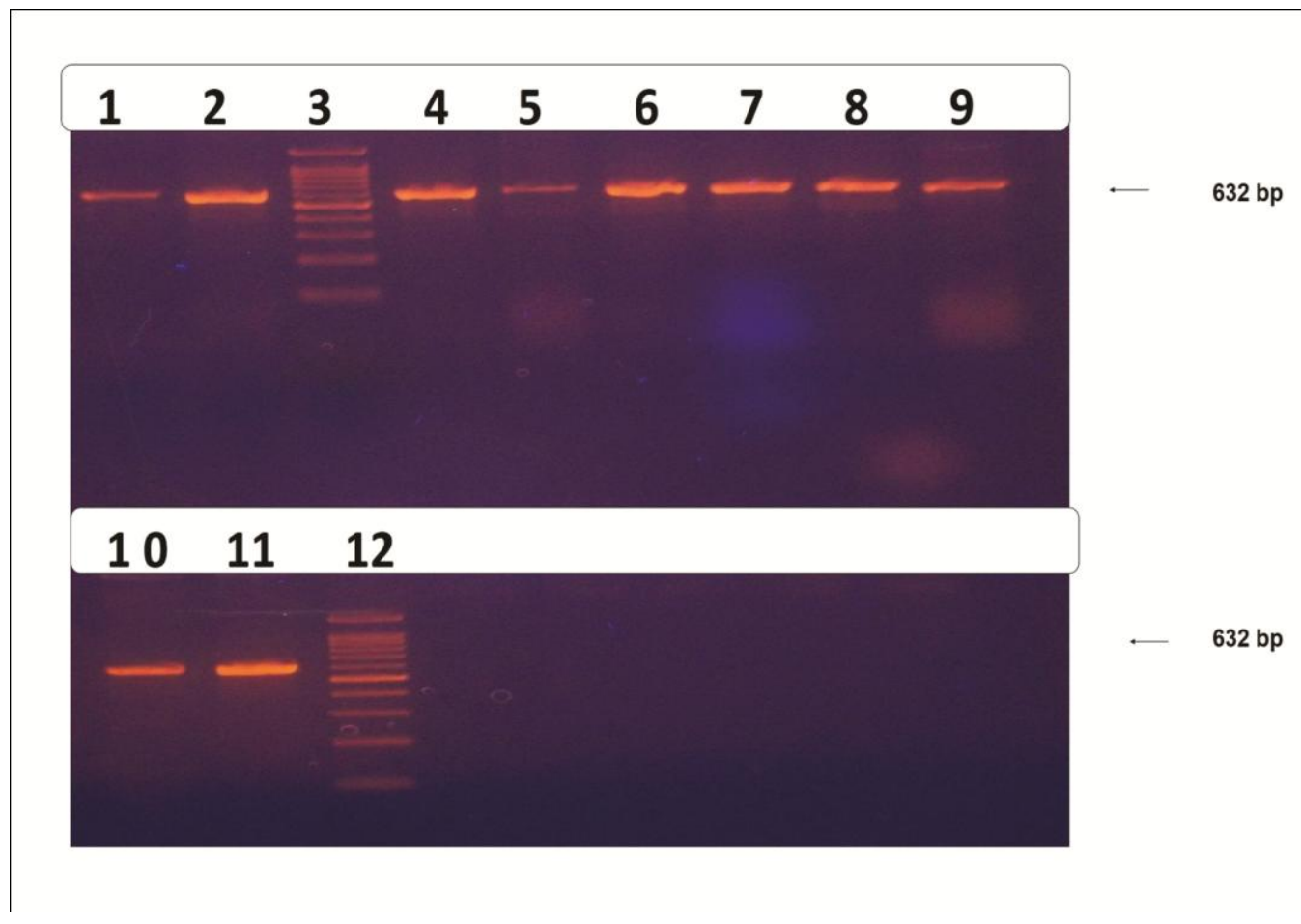

Fig.6 PCR amplification of the 16S rRNA gene using the universal primer pair and the constitutive genes encoding for class D carbapenemases (bla $\left.a_{O X A-48-l i k e}\right)$ in selected CRE clinical isolates. Lanes: 1: 16S rRNA gene (positive control) (1500 bp); 2: negative control; 3: $100 \mathrm{bp}$ DNA ladder; 4: K89 (bla OXA-48-like $_{\text {}}$ (438 bp); 5: K73 (bla OXA-48-like $_{\text {(4) }}$ (438 bp); 6: K40 (bla OXA-48-like $_{\text {) }}$ (438 bp); 7: K92 (bla OXA-48-like) (438 bp); and 8: K77 (bla OXA-48-like $_{\text {(43 }}$ (43p)

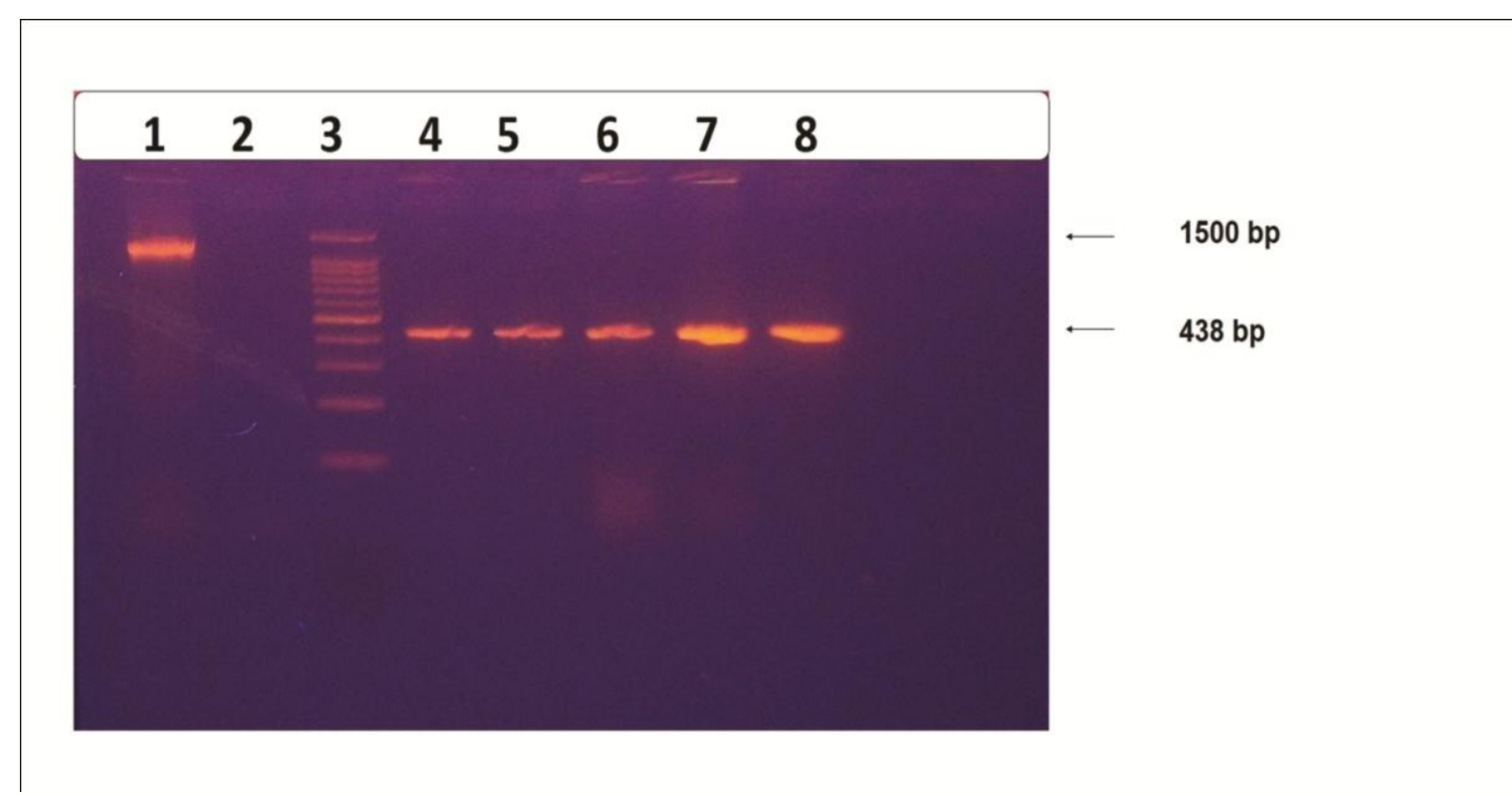


The worldwide spread of CRE has become a great challenge in clinical and public healthcare settings (Yamamoto and PopVicas, 2014). Usually, combination therapy is recommended for the treatment of CRE (Van Duin et al., 2013). Chin and Neu (1987) had previously studied the efficacy of the combination of IPM and CIP against some members of Enterobacteriaceae. They demonstrated that this combination was synergistic only for $22 \%$ of the tested isolates belonging to the Enterobacter spp. In addition, they studied the efficacy of the combination of IPM and RA. They found that, with 32 isolates belonging to the Enterobacter spp., $35 \%$ were synergically inhibited.

Concerning carbapenems/AK combinations, Le et al., (2011) had reported that the combination of MEM or IPM with AK displayed a synergistic activity against all the tested KPC-producing $K$. pneumoniae isolates. Regarding carbapenem/colistin combinations, Souli et al., (2009) studied the efficacy of IPM/COL combination against 42 $K$. pneumoniae clinical isolates carrying a bla $a_{V I M-1}$-type gene. They found that the combination showed improved bactericidal activity against isolates sensitive either to both agents or to colistin.

Schelz et al., (2006) reported that menthol has a significant antiplasmid activity that can approximate $100 \%$. It has been previously assumed that the mechanism of action of menthol is similar to that of the curing agent sodium dodecyl sulphate. The curing agent may be capable of dislodging the plasmid free of its site of attachment, which consequently results in the imperfect replication and unsuccessful segregation of the plasmid (Kai et al., 2002). Also, Kon and Rai (2012) reported that a menthol concentration of 0.325 $\mathrm{mg} / \mathrm{mL}$ resulted in up to a $96 \%$ plasmid elimination. Of course, the variation in the efficacy of the tried concentrations of menthol between different studies could be simply attributed to strain variation.

Yap et al., (2013) had previously emphasized on the potential of peppermint oil being as antibiotic resistance modifying agent. Also, Schelz et al., (2006) reported that the benefit of menthol-antibiotic (s) combinations could be correlated to the antiplasmid activity of menthol. Consequently, they confirmed the significance of peppermint oil and menthol as adjuvant antimicrobial agents by virtue of their antiplasmid activity.

Regarding the results of TEM, the antibacterial activity of menthol had been previously elucidated by Trombetta et al., (2005). They speculated that the antimicrobial effect of menthol may be due to a perturbation of the lipid fraction of the microorganism plasma membrane, thus, leading to alterations of membrane permeability and the leakage of intracellular materials.

Matching with our results, Pavelkovich et al., (2014) had reported the high prevalence of NDM-type carbapenemase-producing $K$. pneumoniae from one Saint Petersburg hospital. In our study, the predominance of $b a_{N D M-1}$ in the tested isolates was considered to be matching with what has been reported in the literature. The international spread of NDM-1 has already been reported in various locations including the Middle East (Ong et al., 2011). In addition, it should be noticed that carbapenem resistance in both isolates $\mathrm{P} 4$ and $\mathrm{K} 62$, in which no carbapenemase genes were detected, could be due to efflux changes co-mediated by chromosomal AmpC $\beta$ lactamase overproduction, as well as outer membrane protein loss (Nagaraj et al., 2012).

Concerning the comparison between phenotypic methods and PCR, it was noticed that all the results were in accordance in case 
of 8 (out of 13 tested) isolates, while a contradiction was detected among the remaining five isolates. This could reveal the poor specificity and sensitivity of the tested phenotypic methods in some cases.

Regarding the comparison between phenotypic and genotypic methods for the detection of carbapenemases, Doyle et al., (2012) reported that PCR had $100 \%$ sensitivity and specificity, while the sensitivity and specificity were $58 \%$ and $93 \%$, respectively, for MHT. For the inhibitor based method, Tsakris et al., (2010) reported that this phenotypic method detected KPC or MBL producers with $100 \%$ sensitivity, as well as the KPC and MBL producers with $96.8 \%$ sensitivity. Also, it should be taken into consideration that the double disc synergy test may have some limitations. EDTA may be able to potentiate the effect of IPM, perhaps because it increases the permeability of the bacterial cell (Vaara, 1992), or because zinc (which EDTA sequesters) potentiates the chemical breakdown of IPM (Baxter and Lambert, 1997).

From this study, we concluded that CRE are becoming widely spread in Egypt, The combinations of carbapenems (IPM or MEM) with CIP, RA, AK or COL have proved their efficacy in vitro for combating CRE. The efficacy of such combinations was much more enhanced by the addition of menthol. Concerning the predominance of the genes encoding for carbapenemases, $b l a_{N D M}$ and bla ${ }_{\text {OXA-48-like }}$ were the most prevalent. PCR was much more preferred than the phenotypic tests for the detection of carbapenemases. Finally, the great significance of the problem of the widespread of CRE in Egypt highlights the importance of the development of new antimicrobial agents and non-traditional antimicrobial methods to overcome the development of resistance towards these lifesaving antibiotics in Egypt.

\section{Acknowledgments}

We thank the technicians of the Electron Microscopy Unit, Faculty of Science, Alexandria University, for their help in the preparation of the bacterial samples examined by the transmission electron microscopy.

\section{References}

Andrews, J. M. (2001). Determination of minimum inhibitory concentrations. $\mathrm{J}$ Antimicrob Chemother, 48, 516.http://dx.doi.org/10.1093/jac/dkf083

Aubron, C., Poirel, L., Ash, R. J. and Nordmann, P. (2005). Carbapenemaseproducing Enterobacteriaceae, U.S. rivers. Emerg Infect Dis, 11 (2), 4. http://dx.doi.org/10.3201/eid1102.030684

Bailey, W. R., Scott, E. G., Finegold, S. M. and Baron, E. J. (1986). Bailey and Scott's Diagnostic Microbiology. Mosby: St. Louis.

Barry, A. L. (1986). Procedure for testing antibiotics in agar media: theoretical considerations. Williams and Wilkins: USA.

Baxter, I. A. and Lambert, P. A. (1997). The effect of zinc on imipenem. Journal of Antimicrobial Chemotherapy, 39, 83839.https://doi.org/10.1093/jac/39.6.838

Cabral, A. B., Melo Rde, C., Maciel, M. A. and Lopes, A. C. (2012). Multidrug resistance genes, including bla (KPC) and bla (CTX)-M-2, among Klebsiella pneumoniae isolated in Recife, Brazil. Rev Soc Bras Med Trop, 45 (5), 572578.http://dx.doi.org/10.1590/S003786822012000500007

Chambers, H. F. and Sande, M. A. (1996). Antimicrobial agents: general considerations. In: Hardman JG, Limbird LE (ed). The pharmacological basis of therapeutics, 9th edn: McGraw-Hill.

Chan, W. C., Li, R. C., Ling, J. M., Cheng, A. F. and Schentag, J. J. (1999). Markedly different rates and resistance profiles 
exhibited by seven commonly used and newer beta-lactams on the selection of resistant variants of Enterobacter cloacae. J Antimicrob Chemother, 43, 5560.https://doi.org/10.1093/jac/43.1. 55

Chan, V., Dreolini, L. F., Flintoff, K. A., Lloyd, S. J. and Mattenley, A. A. (2002). The effect of increasing plasmid size on transformation efficiency in Escherichia coli. Journal of Experimental Microbiology and Immunology, 2, 207223.

Chin, N. X. and Neu, H. C. (1987). Synergy of imipenem - a novel carbapenem, and rifampin and ciprofloxacin against Pseudomonas aeruginosa, Serratia marcescens and Enterobacter species. Chemotherapy, 33, 183-188.http://dx. doi.org/10.1159/000238493

Conly, J. and Johnston, B. (2006). Colistin: the phoenix arises. Can J Infect Dis Med Microbiol, 17, 267-269. http://dx.doi.org/10.1155/2006/901873

Dagert, M. and Ehrlich, S. D. (1979). Prolonged incubation in calcium chloride improves the competence of Escherichia coli cells. Gene, 6, 2328.http://dx.doi.org/10.1016/0378-1119 (79)90082-9

Datta, P., Gupta, V., Garg, S. and Chander, J. (2012). Phenotypic method for differentiation of carbapenemases in Enterobacteriaceae: study from North India. Indian J PatholMicrobiol, 55, 357360.http://dx.doi.org/10.4103/03774929.101744

De Carolis E, Vella A, Vaccaro L, Torelli, R., Spanu, T., Fiori, B., Posteraro, B. and Sanguinetti, M. (2014). Application of MALDI-TOF mass spectrometry in clinical diagnostic microbiology. J Infect DevCtries, $\quad 8, \quad 1081-1088$. http://dx.doi.org/10.3855/jidc.3623

Dimou, V., Dhanji, H., Pike, R., Livermore, D. M. and Woodford, N. (2012). Characterization of Enterobacteriaceae producing OXA-48-like carbapenemases in the UK. J Antimicrob. Chemother, 67,
1660-1665. http://dx.doi.org/10.1093/jac/dks124

Doyle, D., Peirano, G., Lascols, C., Lloyd, T., Church, D. L. and Pitout, J. D. (2012). Laboratory detection of Enterobacteriaceae that produce carbapenemases. J ClinMicrobiol, 50, 3877-3880.http://dx.doi.org/10.1128/ JCM.02117-12

Fernandez-Cuenca, F., Martinez-Martinez, L., Pascual, A. and Perea, E. J. (2003).In vitro activity of azithromycin in combination with amikacin, ceftazidime, ciprofloxacin or imipenem against clinical isolates of Acinobacterbaumannii. Chemotherapy, $\quad 49, \quad 24$ 26.http://dx.doi.org/10.1159/00 0069774

Gupta, N., Limbago, B. M., Patel, J. B. and Kallen, A. J. (2011). Carbapenemresistant Enterobacteriaceae: epidemiology and prevention. Clin Infect Dis, 53, 60-67.http://dx.doi.org/ $10.1093 / \mathrm{cid} / \mathrm{cir} 202$

Hong, S. S., Kim, K., Huh, J. Y., Jung, B., Kang, M. S. and Hong, S. G. (2012). Multiplex PCR for rapid detection of genes encoding class A carbapenemases. Ann Lab Med, 32, 359361.http://dx.doi.org/10.3343/alm. 2012.32.5.359

Horii, T., Kobayashi, M., Sato, K., Ichiyama, S. and Ohta, M. (1998). An in-vitro study of carbapenem-induced morphological changes and endotoxin release in clinical isolates of Gram-negative bacilli. J Antimicrob Chemother, 41, 435-342.

Jamil, I., Zafar, A., Qamar, M. U., Ejaz, H., Akhtar, J. and Waheed, A. (2014). Multidrug resistant Klebsiella pneumoniae causing urinary tract infections in children in Pakistan. Afr. J. Microbiol. Res, 8, 316-319. http:// dx.doi.org/10.5897/AJMR2013.6409

Kaase, M., Szabados, F., Wassill, L. and Gatermann, S. G. (2012). Detection of carbapenemases in Enterobacteriaceae by a commercial multiplex PCR. J Clin. Microbiol, 50 (9), 3115-3118. http://dx. doi.org/10.1128/JCM.00991-12 
Kai, L., Rui, B. and Xue-Ming, Z. (2002). Curing of the Bacillus subtilis plasmid using sodium dodecyl sulfate. Transactions of Tianjin University, 8, 148-151.

Kanj, S. S. and Kanafani, Z. A. (2011). Current concepts in antimicrobial therapy against resistant Gram-negative organisms: extended-spectrum beta-lactamaseproducing Enterobacteriaceae, carbapenemresistant Enterobacteriaceae, and multidrug-resistant Pseudomonas aeruginosa. Mayo ClinProc, 86, 250259.http://dx.doi.org/10.4065/mcp.2010.0 674

Khajuria, A., Praharaj, A. K., Kumar, M. and Grover, N. (2014). Carbapenem resistance among Enterobacterspecies in a tertiary care hospital in Central India. Chemotherapy Research and Practice, 2014, Article ID 972646. http://dx.doi.org/10.1155/2014/972646

Kim, Y., Farrah, S., Baney and R. H. (2007). Membrane damage of bacteria by silanols treatment. Electronic Journal of Biotechnology, $\quad 10, \quad 252-$ 259.http://dx.doi.org/10.2225/vol10issue2-fulltext-7

Kon, K. V. and Rai, M. K. (2012). Plant essential oils and their constituents in coping with multidrug-resistant bacteria. Expert Rev. Anti-Infect. Ther, 10, 775790. http://dx.doi.org/10.1586/ ERI.12.57

Krogstad, D. J. and Moellering, R. C. (1986). Antimicrobial combinations. In : Lorian $\mathrm{V}$ (ed) Antibiotics in laboratory medicine, 2nd edn: Williams and Wilkins.

Le, J., Mckee, B., Srisupha-Olarn, W. and Burgess, D. S. (2011). In vitro activity of carbapenems alone and in combination with amikacin against KPC-producing Klebsiellapneumoniae. J Clin Med Res, 3, 106-110.http://dx. doi.org/10.4021/jocmr551w

Lee, K., Lim, Y. S., Yong, D., Yum, J. H. and Chong, Y. (2003). Evaluation of the Hodge test and the imipenem-EDTA double-disk synergy test for differentiating metallo- $\beta$-lactamase- producing isolates of Pseudomonas spp. and Acinetobacter spp. J. Clin. Microbiol., 41 (10), 4623-4629. http://dx.doi.org/10.1128/JCM.41.10.462 3-4629.2003

Logan, L. K. (2012).Carbapenem-resistant Enterobacteriaceae: an emerging problem in children. Clin Infect Dis, 55, 852859.http://dx.doi.org/10.1093/cid/cis543

Ma, L., Wang, J. T., Wu, T. L.,Siu, L. K., Chuang, Y. C., Lin, J, C., Lu, M. C. and Lu, P. L. (2015). Emergence of OXA-48-producing

Klebsiellapneumoniae in Taiwan. PLoS One, 10, e0139152.http://dx.doi.org/ 10.1371/journal.pone.0139152

Nagaraj, S., Chandran, S. P., Shamanna, P. and Macaden, R. (2012).Carbapenem resistance among Escherichia coli and Klebsiellapneumoniae in a tertiary care hospital in South India. Indian J Med Microbiol, 30, 93-95.http://dx.doi. org/10.4103/0255-0857.93054

Navon-Venezia, S., Chmelnitsky, I., Leavitt, A., Schwaber, M. J., Schwartz, D. and Carmeli, Y. (2006). Plasmid-mediated imipenem-hydrolyzing enzyme KPC-2 among multiple carbapenem-resistant Escherichia coli clones in Israel. Antimicrob Agents Chemother, 50 (9), 3098-3101. http://dx.doi.org/10.1128/ AAC.00438-06

Nordmann, P., Dortet, L. and Poirel, L. (2012). Carbapenem resistance in Enterobacteriaceae: here is the storm! Trends Mol Med, 18, 263272.http://dx.doi.org/10.1016/j.molmed.2 012.03 .003

Ong, D. C., Koh, T. H., Syahidah, N., Krishnan, P. and Tan, T. Y. (2011). Rapid detection of the blaNDM-1 gene by real-time PCR. J AntimicrobChemother, 66, 16471649.http://dx.doi.org/10.1093/jac/dkr184

Papp-Wallace, K. M., Endimiani, A., Taracila, M. A. and Bonomo, R. A. (2011). Carbapenems: past, present, and future. Antimicrob Agents Chemother, 55, 49434960. http://dx.doi.org/10. 1128/AAC.00296-11 
Parveen, R. M., Harish, B. N. and Parija, S. C. (2010). Emerging carbapenem resistance among nosocomial isolates of Klebsiella Pneumoniae in South India. International Journal of Pharma and Bio Sciences, 1 (2).

Pavelkovich, A., Balode, A., Edquist, P., Egorova, S., Ivanova, M., Kaftyreva, L., Konovalenko, I., Kõljalg, S., Lillo, J., Lipskaya, L., Miciuleviciene, J., Pai, K., Parv, K., Pärna, K., Rööp, T., Sepp, E., Jelena Štšepetova, J. and Naaber, P. (2014). Detection of carbapenemaseproducing Enterobacteriaceae in the Baltic countries and St. Petersburg area. BioMed Research International, 2014, Article ID 548960.http://dx.doi.org/ $10.1155 / 2014 / 548960$

Perez, F. and Van Duin, D. (2013). Carbapenem-resistant Enterobacteriaceae: a menace to our most vulnerable patients. Cleve Clin J Med, 80, 225-233.

Phue, J. N., Lee, S. J., Trinh, L. and Shiloach, J. (2008). Modified Escherichia coli B (BL21), a superior producer of plasmid DNA compared with Escherichia coli $\mathrm{K}$ (DH5alpha). BiotechnolBioeng, 101, 831836. http://dx.doi.org/10.1002/ bit.21973

Pitart, C., Solé, M., Roca, I., Fàbrega, A., Vila, J. and Marco, F. (2011). First outbreak of a plasmid-mediated carbapenemhydrolyzing OXA-48 beta-lactamase in Klebsiellapneumoniae in Spain. Antimicrob Agents Chemother, 55, 43984401. http://dx.doi.org/ 10.1128/AAC.00329-11

Podschun, R. and Ullmann, U. (1998).Klebsiella spp. as nosocomial pathogens: epidemiology, taxonomy, typing methods, and pathogenicity factors. ClinMicrobiol Rev, 11, 589-603.

Rozalski, A., Sidorczyk, Z. and Kotelko, K. (1997). Potential virulence factors of Proteus bacilli. MicrobiolMolBiol Rev, 61, 65-89.

Sachan, A. K., Das, D. R., Shuaib, M. D., Gangwar, S. S. and Sharma, R. (2013). An overview on MenthaePiperitae (peppermint oil). IJPCBS, 3, 834-838.
Schelz, Z., Molnar, J. and Hohmann, J. (2006). Antimicrobial and antiplasmid activities of essential oils. Fitoterapia, 77, 279285. http://dx.doi.org/10.1016/j.fitote. 200 6.03 .013

Shahid, M., Umesh, Sobia, F., Singh, A., Khan, H. M., Malik, A. and Shukla, I. (2012). Molecular epidemiology of carbapenemresistant Enterobacteriaceae from a North Indian Tertiary Hospital. N Z J Med Lab Sci, 66, 5-7.

Souli, M., Rekatsina, P. D., Chryssouli, Z., Galani, I., Giamarellou, H. and Kanellakopoulou, K. (2009). Does the activity of the combination of imipenem and colistinin vitro exceed the problem of resistance in metallo-beta-lactamaseproducing Klebsiella pneumoniae isolates? Antimicrob Agents Chemother, 53, 2133-2135. http://dx. doi.org/10.1128/AAC.01271-08

Spengler, G., Molnár, A., Schelz, Z., Amaral, L., Sharples, D. and Molnár, J. (2006). The mechanism of plasmid curing in bacteria. Curr Drug Targets, 7, 823841.http://dx.doi.org/10.2174/138945006 777709601

Trombetta, D., Castelli, F., Sarpietro, M. G., Venuti, V., Cristani, M., Daniele, C., Saija. A., Mazzanti, G. and Bisignano, G. (2005). Mechanisms of antibacterial action of three monoterpenes. Antimicrob Agents Chemother, 49, 2474-2478. http://dx.doi.org/10.1128/ AAC.49.6.2474-2478.2005

Tsai, Y. K., Fung, C. P., Lin, J. C., Chen, J., Chang, F., Chen, T. and Siu, L. K. (2011). Klebsiella pneumoniae outer membrane porins OmpK35 and OmpK36 play roles in both antimicrobial resistance and virulence. Antimicrob Agents Chemother, 55, 1485-1493.http://dx.doi.org/10.1128/ AAC.01275-10

Tsakris, A., Poulou, A., Pournaras, S., Voulgari. E., Vrioni, $\quad$ G., Themeli-Digalaki, K., Petropoulou, D. and Sofianou, D. (2010). A simple phenotypic method for the differentiation of metallo-betalactamases and class A KPC 
carbapenemases in Enterobacteriaceae clinical isolates. J Antimicrob Chemother, 65 , 1664-1671.http://dx. doi.org/10.1093/jac/dkq210

Tu, Z., He, G., Li, K. X., Chen, M. J., Chang, J., Chen, L., Yao, Q., Liu, D. P., Ye, H., Shi, J. and $\mathrm{Wu}, \mathrm{X}$. (2005). An improved system for competent cell preparation and high efficiency plasmid transformation using different Escherichia coli strains. Electronic Journal of Biotechnology, 8, 114-120.

Van Duin, D., Kaye, K. S., Neuner, E. A. and Bonomo, R. A. (2013).Carbapenemresistant Enterobacteriaceae: a review of treatment and outcomes. Diagn Microbiol Infect Dis, 75, 115120.http://dx.doi.org/10.1016/j.diagmicro bio.2012.11.009

Vaara, M. (1992). Agents that increase the permeability of the outer membrane. Microbiol Rev., 56 (3), 395-411.

Wendel, A. F., Brodner, A. H., Wydra, S., Ressina, S., Henrich, B., Pfeffer, K., Toleman, M. A. and MacKenzie, C. R. (2013). Genetic characterization and emergence of the metallo-beta-lactamase GIM-1 in Pseudomonas spp. and Enterobacteriaceae during a long-term outbreak. Antimicrob Agents Chemother, 57, 5162-5165. http://dx. doi.org/10.1128/AAC.00118-13

Yamamoto, M. and Pop-Vicas, A. E. (2014). Treatment for infections with carbapenem-resistant Entero bacteriaceae: what options do we still have?.Crit Care, 18 , 229.

http://dx.doi.org/10.1186/cc13949

Yap, P. S., Lim, S. H., Hu, C. P. and Yiap, B. C. (2013). Combination of essential oils and antibiotics reduce antibiotic resistance in plasmid-conferred multidrug resistant bacteria. Phytomedicine, 20, 710-713. http://dx. doi.org/10.1016/j.phymed.2013.02.013

Zeitoun, H., Kassem, M., Raafat, D., AbouShlieb, H. and Fanaki, N. (2015). Microbiological testing of pharmaceuticals and cosmetics in Egypt. BMC Microbiol, 15, 275. http://dx.doi.org/10.1186/s12866-0150609-z

\section{How to cite this article:}

Nourhan H. Fanaki, Hoda M. Omar, Amal M. Khalil and Eva A. Edward. 2018. Prevalence of Carbapenem Resistant Klebsiella and Proteus Clinical Isolates: A Real Threat to the Egyptian Health Care System. Int.J.Curr.Microbiol.App.Sci. 7(04): 2041-2057. doi: https://doi.org/10.20546/ijcmas.2018.704.235 